\title{
A new species of Cyclograpsus (Brachyura: Varunidae) from Japan, co-occurring with $C$. intermedius Ortmann, 1894
}

\author{
Rie Hangai, Jun Kitaura, Keiji Wada and Yasuo Fukui
}

Abstract.-We report a new species of the semiterrestrial crab of the family Varunidae, Cyclograpsus pumilio Hangai \& Fukui, new species, from the coast of Kii Peninsula, western Japan, which occurs underneath cobbles and boulders piled up at the uppermost level of the intertidal zone. This new species is morphologically most similar to $\mathrm{Cy}$ clograpsus intermedius that sometimes co-occurs with it, but is distinguished mainly by the swollen anterior part of carapace, the presence of granules and long hairs on the anterior and posterior margins of ambulatory legs, the presence of a concavity on the distal margin of the sixth abdominal segment accommodating the penetrating basal margin of the telson in male, and the slightly curved first pleopod of male.

\section{Introduction}

The genus Cyclograpsus H. Milne Edwards, 1837 of the family Varunidae currently contains 19 species ( $\mathrm{Ng}$ et al., 2008), among which 3 species of $C$. integer $\mathrm{H}$. Milne Edwards, 1837, C. longipes Stimpson, 1858, and C. intermedius Ortmann, 1894 are known from Japan (Sakai, 1976).

In the course of life history study on grapsid and varunid crabs, Fukui (1988) discovered an undescribed species of Cyclograpsus on the coast of Shirahama, Wakayama, western Japan. The undescribed species is most similar to $C$. intermedius among so far known Indo-Pacific species of the genus, according to the key provided by
Campbell \& Griffin (1966), in the shape of the lateral margin of the carapace and the number of tubercles on the suborbital ridges. However, clear difference in life history traits between the undescribed species and C. intermedius has been reported (Fukui, 1988). This paper describes the undescribed species as new and provides morphological characteristics that distinguish the new species from allied $C$. intermedius. The type specimens of the new species are deposited in the Osaka Museum of Natural History $(\mathrm{OMNH})$. Body size of the specimens examined is expressed as carapace width $\mathrm{x}$ carapace length.

\section{Taxonomic Account}

Family Varunidae

Subfamily Cyclograpsinae H. Milne Edwards, 1853

Genus Cyclograpsus H. Milne Edwards, 1837

Cyclograpsus pumilio Hangai \& Fukui, new species

(Figs. 1, 2)

[New Japanese name: Mame-akaiso-gani]

Cyclograpsus sp.-Fukui,1988:130-146 (life history data).

Material examined.-Holotype: OMNHAr7736, male $(4.6 \times 4.1 \mathrm{~mm})$, Sakata, Shirahama, Wakayama, Japan, coll. R. Hangai, 28 Aug. 2008.

Paratypes: OMNH-Ar7737, 1 female $(8.8 \times 7.0 \mathrm{~mm})$, same data as holotype; OMNH-Ar7738, 1 male $(4.4 \times 3.9 \mathrm{~mm})$, same data as holotype; OMNH-Ar7739, 1 male 
$(4.9 \times 4.6 \mathrm{~mm})$, Sumiyoshizaki, Ohkawa, Wakayama, Japan, coll. K. Wada, 29 Oct. 2008; OMNH-Ar7740, 1 male $(5.4 \times 5.2 \mathrm{~mm})$, Sumiyoshizaki, Ohkawa, Wakayama, Japan, coll. K. Wada, 29 Oct. 2008; OMNH-Ar7741, 1 female $(8.0 \times 6.4 \mathrm{~mm})$, same data as holotype; OMNH-Ar7742, 1 female $(8.8 \times 7.4$ $\mathrm{mm})$, Sakata, Shirahama, Wakayama, Japan, coll. Y. Fukui, 9 Mar. 2008; OMNH-Ar7743, 1 female $(8.1 \times 6.5 \mathrm{~mm})$, Sakata, Shirahama, Wakayama, Japan, coll. J. Kitaura, 9 Mar. 2008.

Comparative material._Cyclograpsus intermedius Ortmann, 1894. OMNH-Ar7744, 1 male $(19.7 \times 16.3 \mathrm{~mm})$, Sumiyoshizaki, Ohkawa, Wakayama, Japan, coll. K. Wada, 29 Oct. 2008; OMNH-Ar7745, 1 female (16.5 $\times 13.8 \mathrm{~mm}$ ), Sakata, Shirahama, Wakayama, Japan, coll. Y. Fukui, 9 Mar. 2008; OMNHAr7746, 1 male $(22.3 \times 18.8 \mathrm{~mm})$, Sumiyoshizaki, Ohkawa, Wakayama, Japan, coll. R. Hangai, 29 Oct. 2008; OMNH-Ar7747, 1 male $(19.9 \times 17.1 \mathrm{~mm})$, Sumiyoshizaki, Ohkawa, Wakayama, Japan, coll. R. Hangai, 29 Oct. 2008; OMNH-Ar7748, 1 female (16.8 $\times 13.9 \mathrm{~mm}$ ), Sumiyoshizaki, Ohkawa, Wakayama, Japan, coll. K. Wada, 29 Oct. 2008; OMNH-Ar7749, 1 female $(15.7 \times 13.3 \mathrm{~mm})$, Sakata, Shirahama, Wakayama, Japan, coll. Y. Fukui, 9 Mar. 2008.

Description of male-C Carapace (Fig. 1A) subquadrate, slightly broader than long, swollen anteriorly, weakly flattened posteriorly. Lateral margins of carapace parallel; 2 shallow notches behind the external orbital angle, first tooth distinct, second obscure. Posterolateral margins slightly convergent. Dorsal surface of carapace generally smooth, but covered with fine granules on frontal, orbital, and hepatic regions. Front slightly deflexed, divided into 2 weakly convex lobes by very shallow groove, median frontal furrow distinct. Carapace regions obscure, only gastrocardiac groove distinct.

Upper orbital margin concave, slightly oblique. Lower orbital margin (Fig.2A, 2B) with 18-20 small tubercles, becoming less prominent toward outer-lateral corner .

Eyes well developed; ocular peduncle short, base slightly inflated; cornea small, darkly pigmented. Antennule and antenna contiguous. Antennular peduncle relatively large. Antennal peduncle set vertically; flagellum relatively short, but extending into orbit.

Third maxilliped (Fig. 2C) moderately slender. Ischium longer than broad. Merus slightly shorter than ischium, longer than broad, weakly narrowed at base. Ischium and merus with broad longitudinal sulcus and longitudinal row of setae. Inner border of merus and ischium minutely gnanulose with long setae. Dactylus small. Exopod slender, not reaching anterior margin of merus, with well developed flagellum.

Chelipeds (Fig. 2D) symmetrical, smooth. Merus trigonal, with a longitudinal row of short setae on inner surface. Carpus with tuft of setae on inner proximal surface. Palm swollen, smooth, slightly shorter than dactylus. Dactylus and fixed finger smooth with cutting edge dentate.

Ambulatory legs (Figs. 1A, 2F) slender and compressed, second leg longest, fourth leg shortest. Coxae and ischia with sparse setae on ventral surfaces. Meri and carpi trigonal in cross section. Meri with distinctly granulate anterior margins; dorsal surfaces minutely granulate, each with blunt subdistal projection; posterior margin finely serrate (first to third) or slightly serrate (fourth), with 2 rows of long setae (in fourth, stouter setae present in proximal half). Carpi granulated on anterior margin (distal quarter granulated in first and second, distal half in third, entirely in fourth), with dense short setae on distal half in first to third; posterior margin with sparse setae on distal halves in first and third. Propodi each with tufts of setae on anterior margin (first to third) and with 2 rows of long setae on posterior margin (first to third). Dactyli slender, subequal in length to respective propodi; dorsal and ventral surfaces with scattered tufts of setae and posterior margin with 2 rows of setae (first to third). 

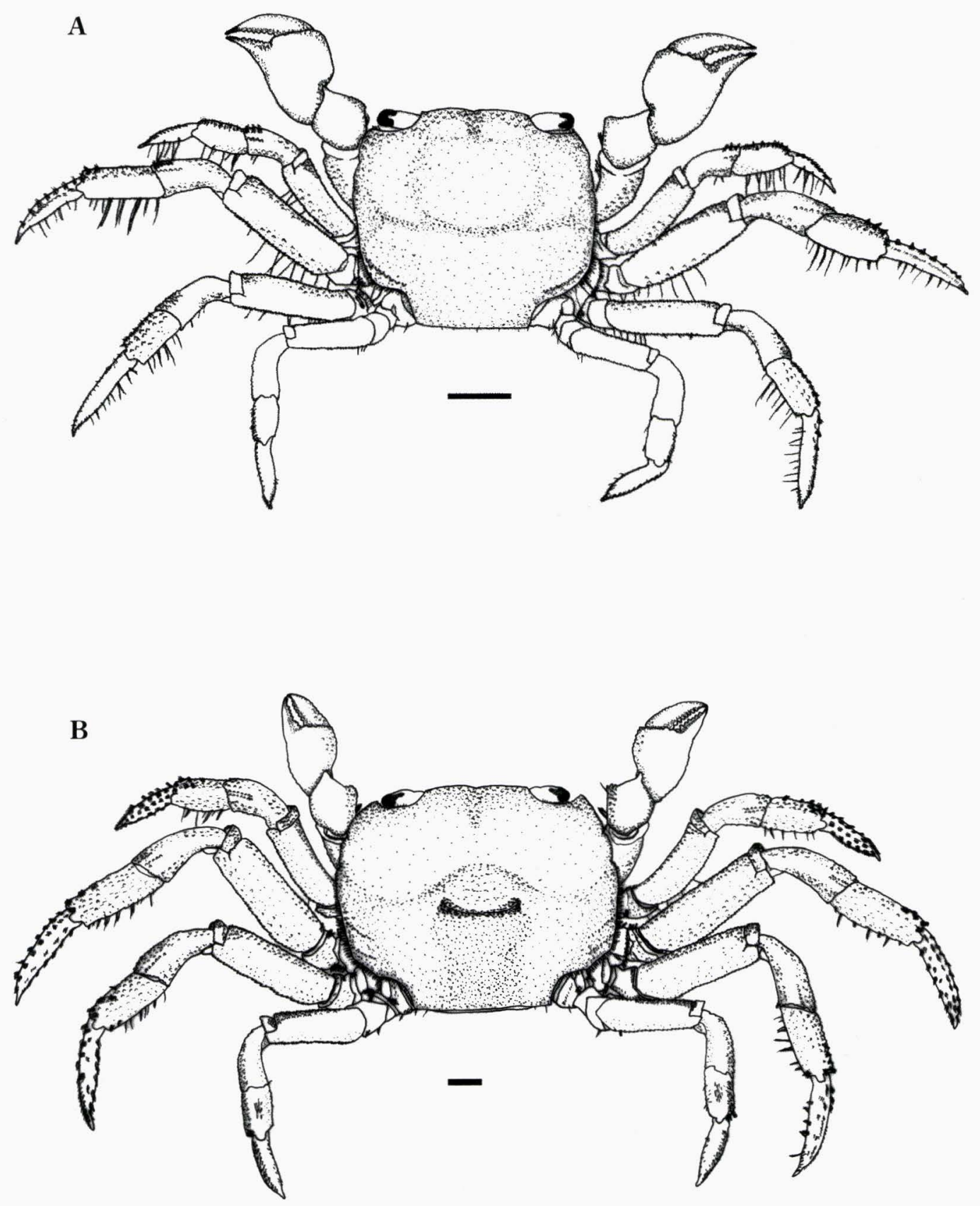

Fig.1. Cyclograpsus pumilio Hangai \& Fukui, new species. A, holotype male $(4.6 \times 4.1 \mathrm{~mm}$; OMNHAr7736) from Sakata, Shirahama, Wakayama, Japan; B, paratype female $(8.8 \times 7.0 \mathrm{~mm}$; OMNH-Ar7737), same data as holotype. Scale bars: $1 \mathrm{~mm}$. 
A

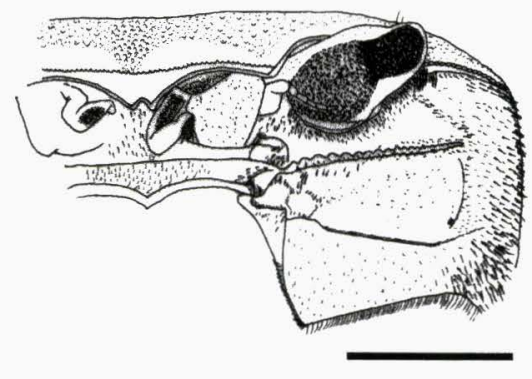

D

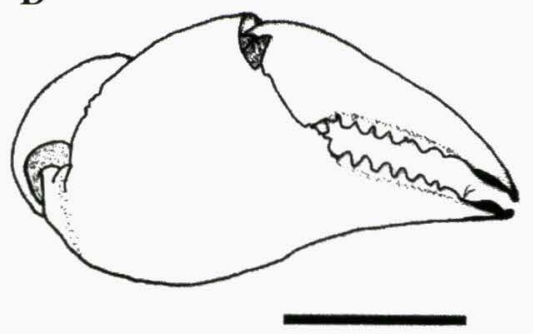

F

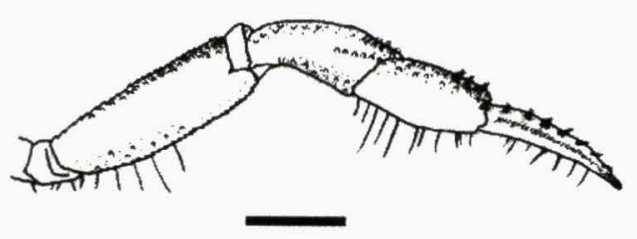

$\mathbf{H}$

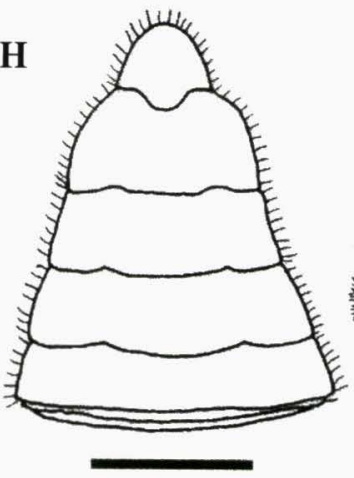

B

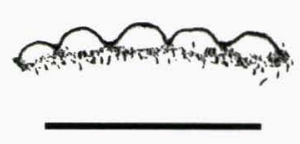

E

C

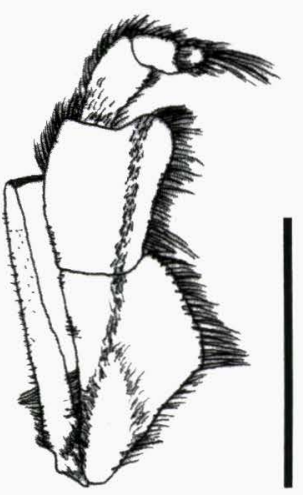

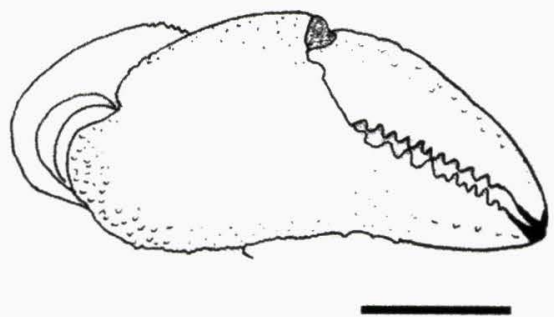

G

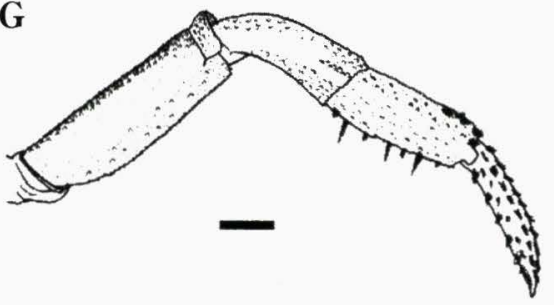

$\mathbf{J}$

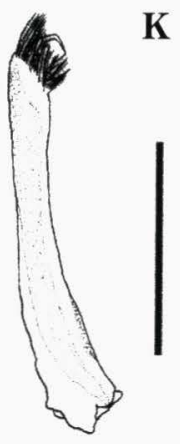

$\mathbf{K}$

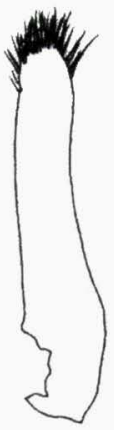

Fig.2. Cyclograpsus pumilio Hangai \& Fukui, new species. A-C, D, F, H, J, K, holotype male from Sakata, Shirahama, Wakayama, Japan; E, G, I, paratype female $(8.8 \times 7.0 \mathrm{~mm}$, OMNH-Ar7737), same data as holotype. A, anterior part of carapace and cephalic appendages, left side anterior view; B, left suborbital ridge, showing inner 5 granules; $\mathrm{C}$, right third maxilliped, outer view; D, E, right chela, outer view; F, $\mathrm{G}$, right second ambulatory leg, dorsal view; $\mathrm{H}$, I, abdomen; J, left first pleopod, mesial view; $\mathrm{K}$, same, ventral view. Scale bars: A, C-L, $1 \mathrm{~mm}$; B, 0.25 mm. 
Abdomen (Fig. 2H) widest near base of third segment, following segments tapering to base of sixth segment, bearing sparse setae on lateral margin. Telson roundly triangular with basal margin projected proximally, penetrating into distal margin of sixth segment.

First pleopod (Figs. 2J, 2K) slightly curved, distally with stiff setae partially obscuring short distal chitinous process and inner lobe.

Description of female.-Carapace (Fig. 1B) slightly proportionally broader than that of male. Cardiac region slightly depressed. Two shallow notches on anterolateral margins more distinct than those of male.

Lower orbital margin with 19-22 small tubercles, more distinct than in male.

Cheliped palm (Fig. 2E) slender with granules on upper and lower margins. Dactylus granulated on upper margin.

First to third ambulatory legs (Figs. $1 \mathrm{~B}, 2 \mathrm{G})$ more granular on dorsal surfaces of meri, carpi, and propodi than in male. Anterior and posterior margins of meri and carpi without setae. Setae on posterior margin of propodi of first to third legs shorter than in male. Dactyli of first to third legs each with 8 rows of tufts of setae.

Abdomen (Fig. 2I) broadly rounded with lateral margins bearing dense setae. Fourth segment widest. Lateral margin of sixth segment strongly curved anteriorly. Telson transversely subtriangular, with basal margin slightly concave backward.

Coloration.-Generally dark brown in dorsal view. Dorsal surface of carapace with white spots in male.

Distribution.-So far known only from two localities in Japan: Sakata, Shirahama, Wakayama, and Sumiyoshizaki, Ohkawa, Wakayama.

Ecological note.-This species occurs underneath cobbles and boulders piled up at the uppermost level of the intertidal zone, intermingling with $C$. intermedius. The maximum size of females $(9.5 \mathrm{~mm} \mathrm{CW})$ is markedly larger than that of males (5.0 mm CW) (Fukui, 1988). Breeding season (the period when ovigerous females occur) lasted about 4 months from late May to late September, with the peak in June and September (Fukui, 1988), differing from that of C. intermidius lasting 8 months of March to October (Fukui, 1988).

Etymology.-The specific name is derived from small body size of males compared to females. "Pumilio" stands for dwarf in Latin.

Remarks.-Ortmann's (1894) original description of $C$. intermedius is rather brief, but is still informative to confirm the specific identity of his taxon. Cyclograpsus pumilio, new species, is morphologically similar to C. intermedius, but is distinguishable by the following characters: in C. pumilio, anterior part of the carapace is swollen, and the surface covered with fine granules (the carapace is flattened, and the surface smooth in C. intermedius, see Fig.3A); the external orbital angle of $C$. pumilio is blunt (subacute in $C$. intermedius); the tubercles on the lower orbital margin are less distinct in $C$. pumilio than in C. intermedius (see Figs. 3B, $3 C)$; ambulatory legs bear long setae on the posterior margin of meri and propodi in $C$. pumilio (setae absent in $C$. intermedius; see Fig. 3G); the merus of each ambulatory leg is distinctly granulate on the anterior margin and is finely serrated on the posterior margin in C. pumilio (smooth in C. intermedius); and the male abdomen is widest near the base of the third segment in $C$. pumilio (widest near the base of the first segment in $C$. intermedius; see Fig.3I). Moreover, the basal margin of the telson of male penetrates into the sixth segment in $C$. pumilio, while the margin is straight in C. intermedius (Fig. 3I). The male first pleopod is slightly curved in C. pumilio versus straight in $C$. intermedius (Figs. 3K, 3L); setae on the distal chitinous process of $C$. pumilio is longer than that of C. intermedius. Sexual dimorphism in body size is different between the two species, i.e. female-biased in $C$. pumilio but in $C$. intermedius male-biased (Fukui, 1988).

Cyclograpsus intermedius is distributed in Japan from Hokkaido to Okinawa (Sakai, 
A

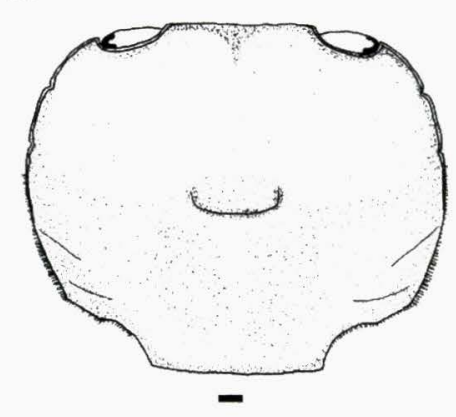

E
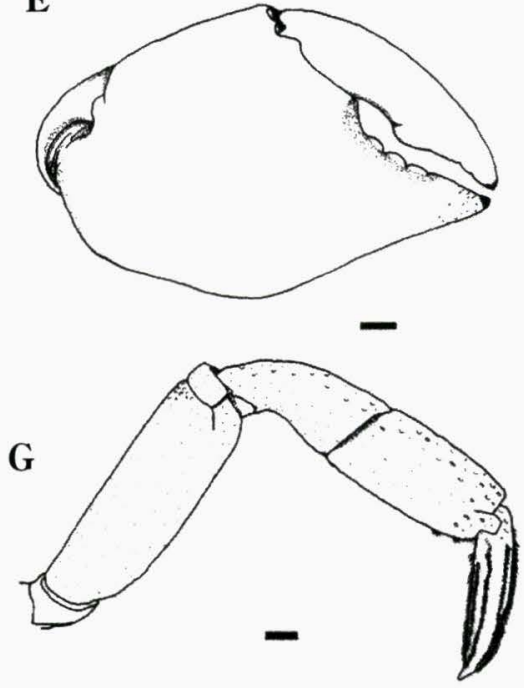

B

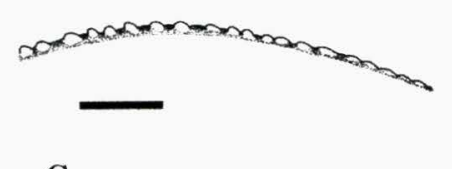

$\mathrm{C}$

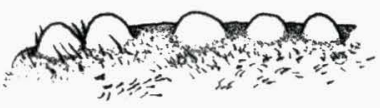

D

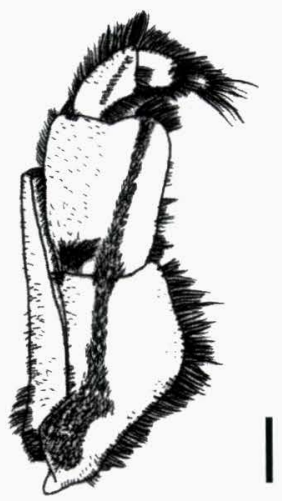

$\mathbf{F}$

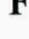

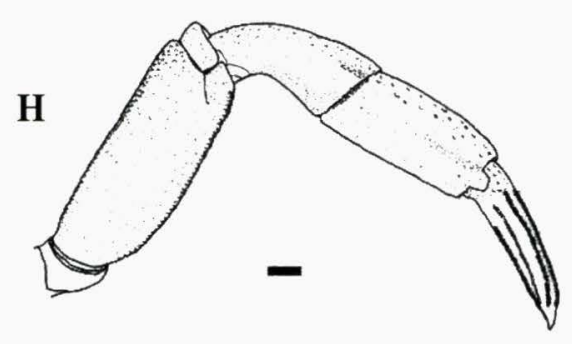
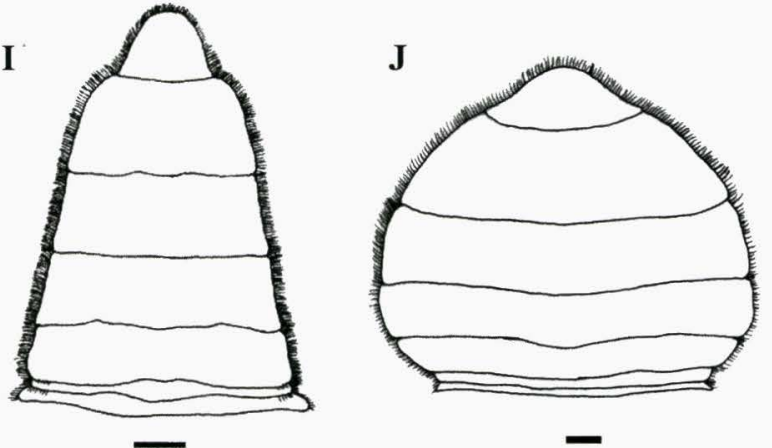

$\mathbf{K}$
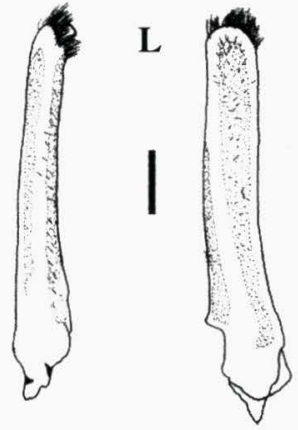

Fig.3. Cyclograpsus intermedius (Ortmann, 1894). A-C, E, G, I, K, L, male $(19.7 \times 16.3 \mathrm{~mm}$, OMNHAr7744) from Sumiyoshizaki, Ohkawa, Wakayama, Japan; D, male (22.3 × $18.8 \mathrm{~mm}$, OMNH-Ar7746), from Sumiyoshizaki, Ohkawa, Wakayama, Japan; F, H, J, female, (16.5 × 13.8 mm, OMNH-Ar7745) from Sakata, Shirahama, Wakayama, Japan. A, carapace, dorsal view; B, left suborbital ridge; C, inner 5 granules of left suborbital ridge; $\mathrm{D}$, right third maxilliped, outer view; $\mathrm{E}, \mathrm{F}$, right chela, outer view; $\mathrm{G}$, $\mathrm{H}$, right second ambulatory leg, dorsal view; I, J, abdomen; K, left first pleopod, mesial view; L, left first pleopod, ventral view. Scale bars: $1 \mathrm{~mm}$. 
1976, Miyake, 1983), Taiwan (Sakai, 1976), Korea (Kim \& Kim, 1982), and Indian Ocean (Ortmann, 1894). But $C$. pumilio has so far been found only from two localities of Wakayama Prefecture, western Japan. Furthermore, the habitat of $C$. pumilio is limited to the narrow uppermost level of the intertidal zone of the boulder shore, which easily suffers destruction by anthropogenic shoreline development. Therefore, conservation status of the new species should be urgently assessed.

\section{Acknowledgements}

We express our appreciation to Dr. Y. Yusa and other members of the laboratory of Animal Ecology, Nara Women's University for their valuable comments and support. Review and useful comments on the manuscript by Drs. C. L. McLay, T. Komai and T. Naruse are also acknowledged.

\section{Literature Cited}

Campbell, B., \& Griffin, D. J. G., 1966. The Australian Sesarminae (Crustacea: Brachyura): genera Helice, Helograpsus nov., Cyclograpsus, and Paragrapsus. Memoirs of the Queesland Museum, 14: 127-174, pls.20-23.

Fukui, Y., 1988. Comparative studies on the life history of the grapsid crabs (Crustacea, Brachyura) inhabiting intertidal cobble and boulder shores. Publication of the Seto Ma- rine Biological Laboratory, 33: 121-162.

Kim, W., \& Kim, H., 1982. Classification and geographical distribution of Korean crabs (Crustacea, Decapoda, Brachyura). Proceedings of the College of Natural Sciences, Seoul National University, 7: 133-159.

Miyake, S., 1983. Japanese Crustacean Decapods and Stomatopods in Color, Vol. II. Hoikusha, Osaka, 277pp., 64pls.

Ng, P. K. L., Guinot, D., Davie, P. J. F., 2008. Systema Brachyurorum: Part I. An annotated checklist of extant brachyuran crabs of the world. The Raffles Bulletin of Zoology, 17: 1-286.

Ortmann, A., 1894. Die Decapoden-Krebse des Strassburger Museums, mit besonderer Berücksichtigung der von Herrn Dr. Döderlein bei Japan und bei den Liu-Kiu-Inseln gesammelten und zur Zeit im Strassburger Museum aufbewahrten Formen VIII. Theil. Abtheilung: Brachyura (Brachyura genuine Boas) III. Unterabtheilung: Cancroidea, 2 Section: Cancrinea, 2. Gruppe: Catametopa. Zoologische Jahrbücher, Abtheilung für Systematik, Geographie und Biologie der Tiere, 7: 683-772, pl. 23.

Sakai, T., 1976. Crabs of Japan and the Adjacent Seas: 461 pp. +773 pp. +251 pls., Kodansha, Tokyo.

Addresses: (RH) (JK) (KW) Department of Biological Sciences, Faculty of Science, Nara Women's University, Nara 630-8506, Japan; (YF) Course of General Education, Osaka University of Arts Junior College, Osaka 546-0023, Japan

Email: (KW) mbanzai@cc.nara-wu.ac.jp; (YF) fukuiy@mahoroba.ne.jp 